\title{
Leak Detection, Localization, and Prognosis of High Pressure Fuel Delivery System
}

\author{
Azeem Sarwar ${ }^{1}$, and Xiangxing $\mathrm{Lu}^{2}$ \\ 1,2 Vehicle Health Management Group, Vehicle Systems Research Laboratory, General Motors Company, \\ 30565 William Durant Blvd, Warren, MI, USA \\ azeem.sarwar@gm.com \\ xiangxing.lu@gm.com
}

\begin{abstract}
Spark Ignition Direct Injection (SIDI) technology enables better fuel economy and tail pipe emissions in vehicles equipped with gasoline engines. The SIDI technology relies on the system's ability to deliver fuel at high pressures (20-40 MPa). Such high pressure systems are prone to leakage if subjected to excessive vibrations, improper fitting, or failure of pressure seals over time due to cyclical loading. Fuel leakage can directly affect the operation of the engine and can cause customer inconvenience. It, therefore, becomes very important to devise a scheme that can effectively diagnose and prognose such kind of system fault. In this report, algorithm development for diagnosis and prognosis of leaks in high pressure fuel delivery system is presented. In particular, pressure profile of fuel in the common rail at engine cranking and engine shutdown are studied to generate schemes for fault detection, fault isolation, and fault prediction. The developed results are equally applicable to direct injection diesel engines given their similarity of operating principles and components.
\end{abstract}

\section{INTRODUCTION}

The automotive industry has witnessed significant progress in the development and proliferation of direct injection internal combustion engines over the last two decades. The technology enablers, namely advanced computer control and fast actuation response of fuel injectors, kick started simultaneous development in diesel as well as gasoline engines in the mid-90s, and was prompted by stricter emission regulations, and increasing fuel economy and efficiency requirements (see (Ferguson \& Kirkpatrick, 2015) for details). However, direct injection gasoline engines were slower to market penetration compared to direct injection diesel engines, attributed mainly to relatively high cost, lower than expected gains in fuel economy and full-load performance, and the requirement

\footnotetext{
Azeem Sarwar et al. This is an open-access article distributed under the terms of the Creative Commons Attribution 3.0 United States License, which permits unrestricted use, distribution, and reproduction in any medium, provided the original author and source are credited.
}

for a lean $\mathrm{NO}_{x}$ aftertreatment system. In comparison, the high-speed direct injection diesel engine achieved commercial success faster due to its excellent fuel economy and good performance characteristics (Zhao, 2009).

Figure 1 shows penetration of diesel engines into passenger cars in Western Europe in the last two decades, based on the information populated by European Automobile Manufacturers' Association (ACEA). The diesel proportion can be seen to ramp up in 1997 crossing over $50 \%$ in 2006 . In the last decade, diesel engines have enjoyed more then $50 \%$ share in the passenger cars on average which amounts to approximately 7.5 million vehicles. The increase in diesel proportion in Europe is due in part to the improvements in specific power and torque, with specific power reaching $75 \mathrm{~kW} /$ litre enabled by the modern high-speed direct injection diesel engines (Zhao, 2009). In addition, the recent achievements in refinements, with new sophisticated fuel injection systems reducing combustion noise, are giving gasoline-like-in-vehicle noise and vibration levels. This is evident with the adoption of diesel engines in top of range models of premium luxury manufacturers (Baude, Froehlich, W., H., \& E., 2008).

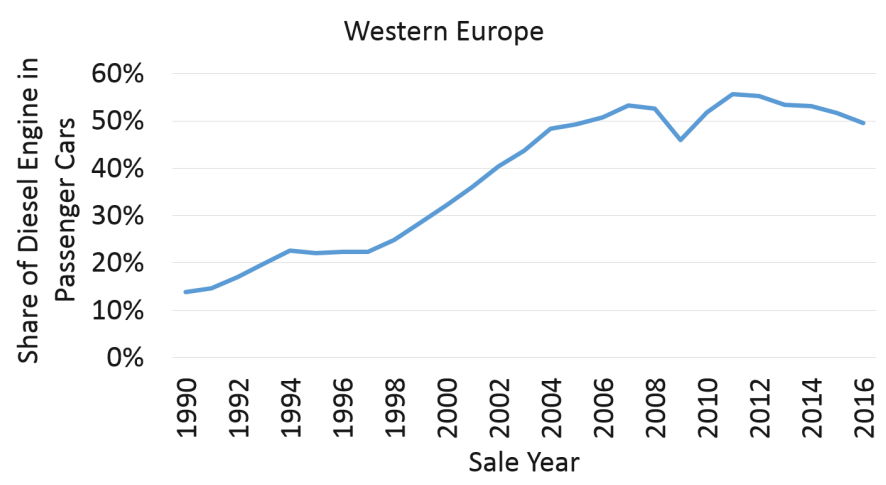

Figure 1. Share of Diesel Engines in European Market (Cars \& Light Trucks) 
As mentioned above, the penetration of gasoline direct injection into the market was slower compared to diesel engines, and started to appear only in 2008 in the United Stated (see Figure 2) as reported by EPA ("Light-Duty Automotive Technology, Carbon Dioxide Emissions, and Fuel Economy Trends: 1975 Through 2016", 2016). Most of the market was dominated by the port fuel injection technology up until 2016 , where the port fuel injection and direct injection technologies are seen to be in parity. Going forward, the gasoline direct injection engines are expected to capture $80 \%$ of the market in the United States by 2023 according to Information Handling Services (see (Sarwar, Sankavaram, \& Lu, 2017) for more details).

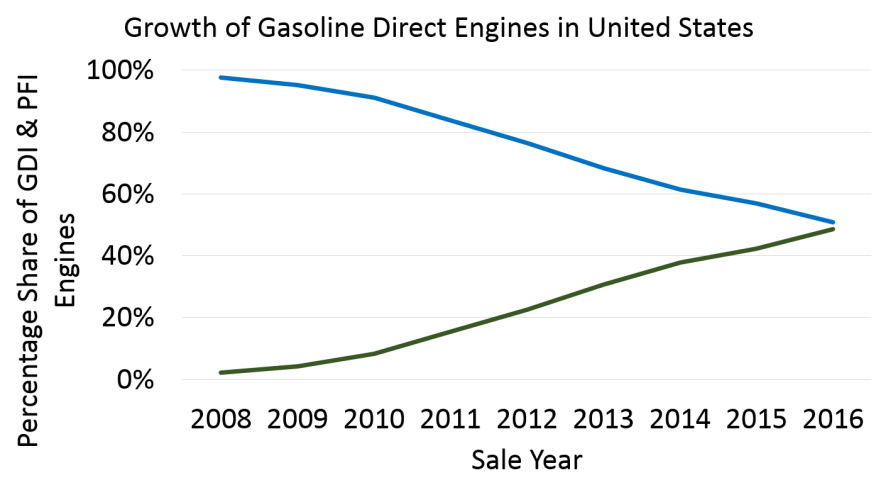

Figure 2. Share of Gasoline Direct Injection Engines (green) against Port Fuel Injection Engines (blue) in United States (Cars \& Light Trucks)

Direction injection engines operate at very high pressures to enable quick delivery of fuel against high combustion chamber pressures (up to $4 \mathrm{MPa}$ ), better fuel atomization, and mixture motion. Direct injection diesel engines have operating pressures of up to $200 \mathrm{MPa}$ (Schaschke, Fletcher, \& Glen, 2013). In contrast, gasoline engines currently operate at pressure of about $20 \mathrm{MPa}$ and are increasing to $40 \mathrm{MPa}$ going forward (Hoffmann, Befrui, Berndorfer, Piock, \& Varble, 2014). The increased pressure in gasoline engines will result in droplet size decrease from $19 \mu \mathrm{m}$ to $14 \mu \mathrm{m}$ (normalized to injector opening of $7 \mathrm{mg} /$ pulse), a reduction that will also help reduce Stochastic Pre-ignition - a phenomenon that is reported in turbocharged gasoline direct injection engines that can lead to piston damage (He, Liu, Stahl, Zhang, \& Zheng, 2016). Leakage of fuel delivery systems and fuel injectors can be an element of concern in direct injection fuel delivery systems since they operate at high pressures (Krogerus, Hyvönen, \& Huhtala, 2016). The pressure lines of the fuel delivery system are subjected to vibrations coming mainly from the impact action and the inertia of moving components, as well as the pressure wave during burning in cylinder. Based on theory and calculation, it is stated in (Kang \& Hu, 2004) that the vibration of the fuel system is mainly caused by the Bourdon
Effect of high-pressure pipe. This kind of vibration can cause wear at the tie-in resulting in leakage of the fuel system and should, therefore, be monitored.

None of the on-board diagnostics (OBD) are designed to detect these fuel system leaks. The OBD regulations, to this date, are directed towards emission controls and the ability of a vehicle to identify (and not necessarily isolate) a fault that could affect emissions in any manner possible. Nonetheless, the service industry relies on the diagnostic trouble codes generated by the OBD system for the servicing of parts and components. In cases like above, it is difficult to isolate the root cause of the problem using OBD system, and hence results in erroneous replacements of parts on a vehicle, increasing warranty expenditure and inconvenience on part of the customer. With the advent of ubiquitous internet connectivity ("World Internet Users Statistics and 2017 World Population Stats", 2017), cellular phone proliferation ("Digital in 2017: Global Overview", 2017), tremendous increase in computational power, together with successful application of sophisticated machine learning algorithms (Silver et al., 2016), the time is right for a paradigm shift in vehicle diagnostics, service, and maintenance. Leveraging these technological advancements, together with physics of failure principles, GM launched OnStar ${ }^{\mathrm{TM}}$ Proactive Alerts service that is designed to provide early warning to customers in case a component failure is impending, thereby turning emergency repair services into scheduled maintenance events. In addition, knowledge of a component's health can directly help the service technicians to diagnose the correct fault and identify the faulty systems and components thereby reducing the no trouble found cases and decreasing the associated warranty costs.

Naturally, components and systems that are critical to vehicle driveability and safety are targeted first for development of such technologies. The fuel delivery system of direct injection engine is one such system. This article provides a detailed development of prognostic technologies related to leak detection of direct injection fuel delivery system. These leaks can occur due to failure of seals, over stressing of high pressure fuel hose tie-in joints, failure of O-rings in injectors, and excessive clearance in high pressure pump due to erosion. Such leaks can lead to a decreased efficiency of the engine, decreased fuel economy, and eventually loss in power resulting in a towing or a walk home incident for the customer. The developments reported in this article are focused on avoiding such inconvenient situations for the customer, and will help enhance the perceived reliability and quality of GM vehicles. In addition, they will provide peace of mind to the customers, reduce warranty cost by elimination of no trouble found cases, and ensure timely detection and isolation of faults so that corrective mitigation and maintenance measures can be taken. 
We note here that in the United States, $99 \%$ of internal combustion engine vehicles (cars, and light trucks) are gasoline based ("Light-Duty Automotive Technology, Carbon Dioxide Emissions, and Fuel Economy Trends: 1975 Through 2016”, 2016). In development of the prognostics technologies mentioned above, we therefore restrict our focus on the direct injection gasoline engines referred to as Spark Ignition Direct Injection (SIDI) in rest of this article. The working principle, and the components used in SIDI fuel delivery systems are very similar to the ones employed in the diesel direct injection fuel delivery systems and thus the technology developed here has a direct application in diesel engines. The rest of the article is organized as follows. Section 2 describes the SIDI High Pressure Fuel Delivery System including some basic modeling principles for fuel delivery system leak. Section 3 describes leak detection methodology, and apparatus used to develop it. Section 4 explains how we can use the methodology developed in Section 3 to localize the fault and develop prognosis of the high pressure fuel delivery system.

\section{High Pressure fuel Delivery System}

A typical SIDI system for a four cylinder application is shown in Figure 3. In SIDI systems, gasoline is injected directly into the combustion chamber through fuel injectors. This requires gasoline to be at high pressure. The high pressure fuel pump compresses and pushes necessary amount of fuel into the fuel rail by precisely opening and closing a solenoid valve in order to maintain the required pressure. The electric fuel pump which is present in Port Fuel Injection systems delivers fuel from the tank to the inlet of the high pressure fuel pump. The high pressure fuel pump then increases the fuel rail pressure from a pump inlet line pressure of 0.3 to $0.5 \mathrm{MPa}$ to a range of 1 to $20 \mathrm{MPa}$. Fuel injectors on each bank are connected to a common fuel rail. Each injection event removes fuel from the fuel rail, resulting in a decrease in fuel rail pressure. Each pumping event of the high pressure fuel pump, on the other hand, adds fuel to the fuel rail to increase the pressure. The pressure profile of the fuel rail, therefore, oscillates around a pressure set point for a fixed operating condition.

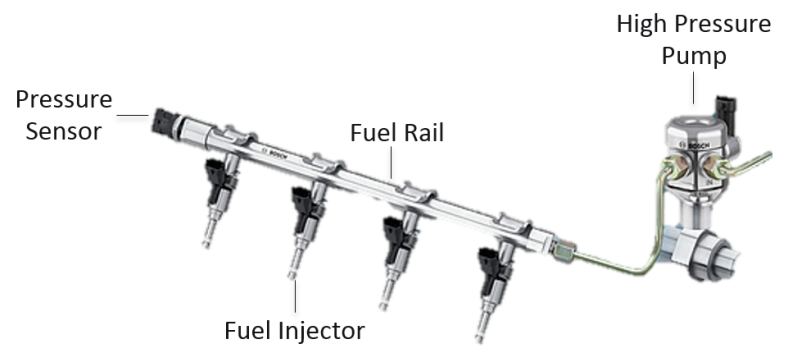

Figure 3. Schematic of High Pressure Fuel Delivery System

A cross section of a typical SIDI high pressure fuel pump is shown in Figure 4. It is a variable displacement fuel pump with a single piston mechanically operated by a multi-lobe (3 or 4 lobes) cam. The solenoid valve, which consists of a needle plunger and an electromagnetic coil, is used to control the flow rate into the pumping chamber, and thus controls the pressure in the fuel rail. The pressure rise in the pumping chamber can be described by the following equation:

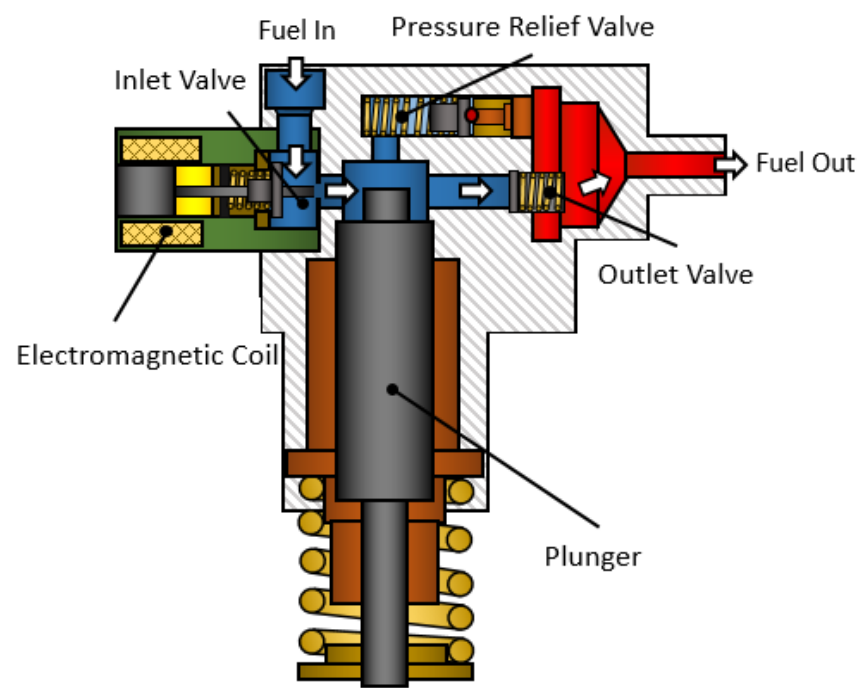

Figure 4. Cross Section of High Pressure Fuel Pump

$$
\frac{d p}{d t}=\frac{B\left(Q_{\text {in }}-Q_{\text {out }}-Q_{\text {leak }}\right)}{V_{\text {pump }}(t)}
$$

where, $p$ is the pressure in the pumping chamber, $B$ is the Bulk Modulus of the fuel, $Q_{i n}$ is the fuel flow into the pumping chamber, $Q_{\text {out }}$ is the flow out of the pumping chamber into the fuel rail, $Q_{\text {leak }}$ is the fuel that leaks out of the pumping chamber, and $V_{\text {pump }}(t)$ is the volume of the pumping chamber.

\subsection{High Pressure Fuel Rail Modeling}

The SIDI high pressure fuel rail can be modeled as a reservoir with fixed volume. The inlet of the fuel rail connects to the high pressure fuel pump through a check valve. The fuel in the pumping chamber must be higher than that in the fuel rail plus the cracking pressure of the check valve for it to flow into the fuel rail. The fuel exits from the fuel rail either through the fuel injectors or any potential leaking orifice. When the injection is turned off, such as at the time of engine cranking, deceleration fuel cutoff, or engine shutdown, the fuel rail model can be simplified to a fixed volume reservoir with single inlet (fuel coming in through the high pressure pump) and single outlet (orifices where leak can happen) as shown in Figure 5. Note that multiple leaks can be lumped together and modeled as one single orifice. 


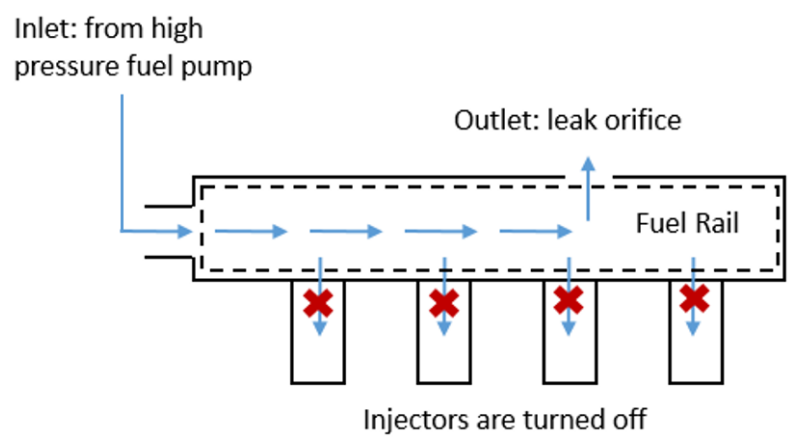

Figure 5. High Pressure Fuel Rail Model

The pressure change in the fuel rail can be described by an equation similar to one described by Equation (1), but in this case, $Q_{\text {out }}$ is zero as the injectors are turned off. Therefore, the equation can be re-written as follows:

$$
\frac{d p}{d t}=\frac{B\left(Q_{\text {in }}-Q_{\text {leak }}\right)}{V_{\text {rail }}}
$$

where $p$ is the pressure in the fuel rail, $B$ is the Bulk Modulus of the fuel, $Q_{i n}$ is the fuel flow that enters into the fuel rail, $Q_{\text {leak }}$ is the fuel that leaks out of the fuel rail, and $V_{\text {rail }}$ is the volume of the fuel rail, which is a constant. Converting the volumetric flow rate to mass flow rate, the equation can be written as:

$$
\frac{d p}{d t}=\frac{B\left(\dot{m}_{\text {in }}-\dot{m}_{\text {leak }}\right)}{m_{\text {rail }}}
$$

where $\dot{m}_{i n}$ is the fuel mass flow rate into the rail, $\dot{m}_{\text {leak }}$ is the fuel mass flow rate that leaks out of the rail, and $m_{\text {rail }}$ is the mass of fuel that fills up the rail volume. Integrating both sides of Equation (3) within a small time period $\Delta t$, the relationship between the fuel mass and fuel rail pressure change can be described as follows:

$$
m_{\text {in }}-m_{\text {leak }}=\frac{m_{\text {rail }}}{B(p, T)} \Delta p
$$

where $\Delta p$ is the pressure change during the time period $\Delta t$, and $B(p, T)$ is the Bulk Modulus of the fuel, which is a function of pressure and temperature.

\section{Leak Detection in High Pressure fuel De- LIVERY SYSTEM}

\subsection{Leak Detection Based on System Performance at En- gine Cranking}

Injection does not start immediately at engine cranking since it usually takes a few pumping strokes to raise the rail pressure to the minimum pressure required for fuel injection. In this initial cranking phase, the high pressure fuel pump is simply building up the pressure in the fuel rail without any fuel being injected into the combustion chamber. Since the high pressure fuel pump is driven by the crankshaft with a multilobe cam, each pumping stroke will raise the rail pressure by a certain amount as shown in Figure 6.

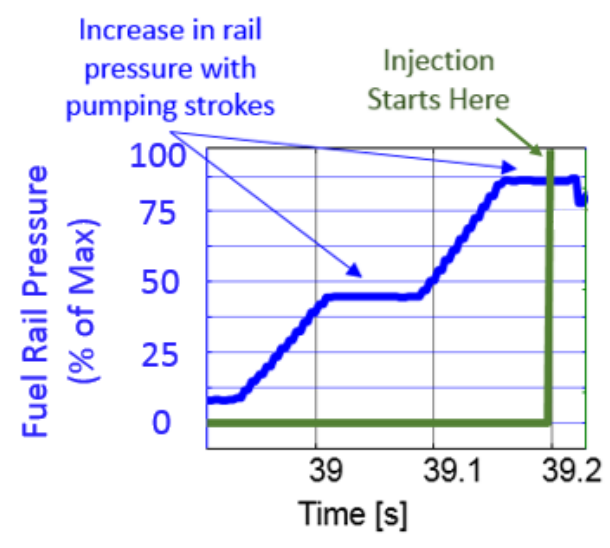

Figure 6. Pressure Rise During Engine Cranking

Based on Equation 4, define $\Delta p_{\text {stroke }}$ as the pressure rise due to each pumping stroke during the time $\Delta t$, we can rewrite Equation (4) as follows:

$$
m_{\text {in }}-m_{\text {leak }}=\frac{m_{\text {rail }}}{B(p, T)} \Delta p_{\text {stroke }}
$$

A Chevrolet Silverado vehicle (Model Year 2014) equipped with a 4.3L V6 engine was instrumented to simulate the leak in the fuel delivery system. The system built for fault injection is shown in Figure 7 with the vehicle shown in a), while the top view of engine block with air intake manifold removed is shown in b). The fuel rails for both banks are connected with a high pressure housing, and serve as a single reservoir for fuel. The bottom fuel rail was modified and a tap was made at its end, as highlighted in c). A high pressure housing connected this tap to the inlet of a Clark Cooper EH40 digital valve (on/off) that is rated at 10,000 psi as shown in d). This valve is controlled by an electric relay which was further instrumented to be controlled by a remote control unit (not shown). The outlet of this digital valve was then connected to a Swagelok SS-31RS4 manually controlled needle valve rated at 3,000 psi as shown in e). A low pressure housing then connected the outlet of the needle valve to the vehicle's fuel tank labeled as f). When the digital valve opens, it allows fuel from the fuel rail to flow down to the needle valve. The needle valve then regulates the amount of fuel that is allowed to leak out of the fuel rail system back into the fuel tank.

To summarize, the leak can be turned on or off by turning the digital valve on or off, and the amount of leak can be controlled manually through the needle valve. Figure 8 shows the pressure rise during engine cranking in the fuel rail within one pumping stroke with (red curve) and without (blue curve) the 


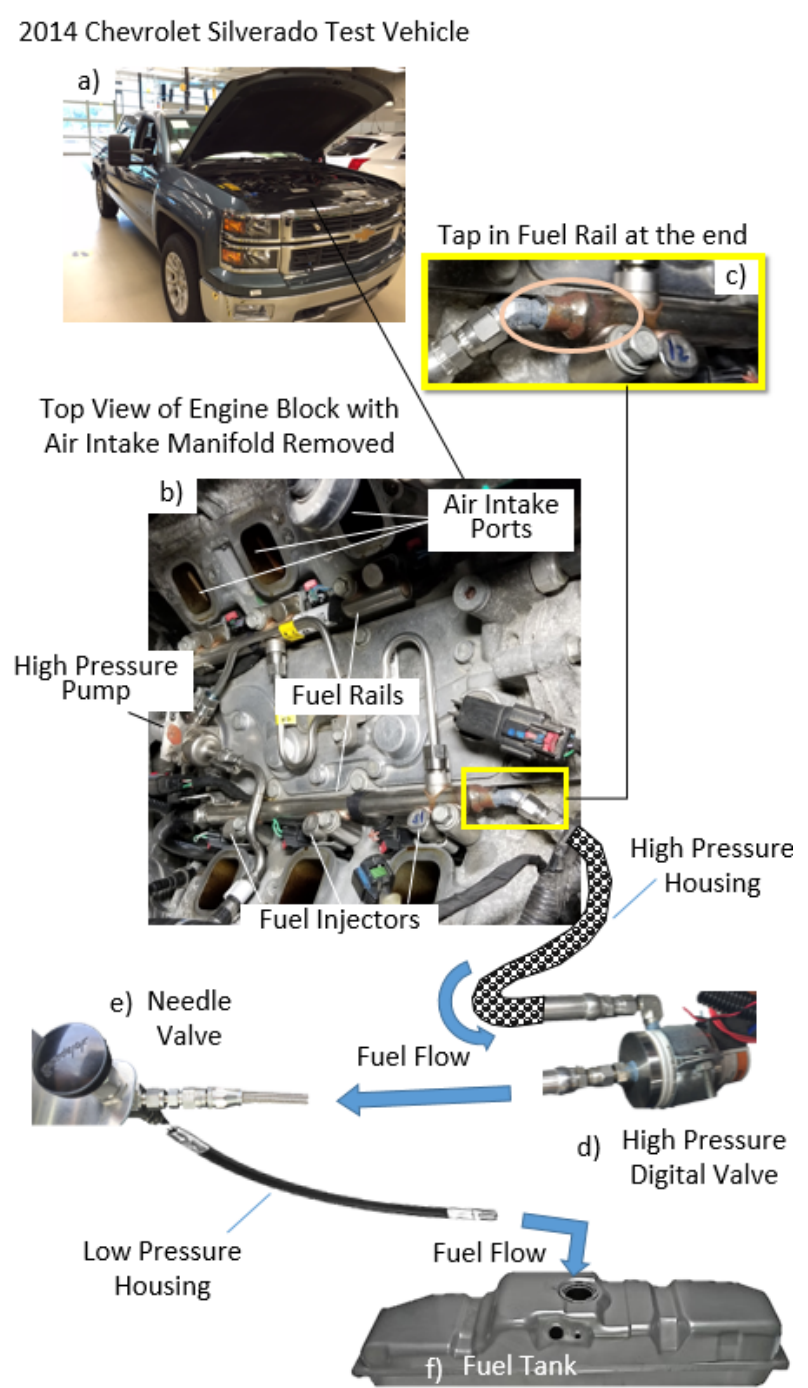

Figure 7. Setup for Introducing Variable Leak into the High Pressure Fuel Delivery System.

leak fault being injected. The pressure difference between the blue and red curves was due to the fact that a certain amount of fuel was allowed to leak out of the fuel rail in the case of the red curve.

For the nominal case where no leak fault is injected, the pressure rise within this pumping stroke from point $A$ to point $B_{1}$ is given by,

$$
\Delta p_{\text {nominal }}=p_{B 1}-p_{A} .
$$

where $p_{A}$ and $p_{B 1}$ are the fuel pressures measure at the beginning and end of the pumping stroke respectively. Since $m_{\text {leak }}=0$, Equation (5) can be written as,

$$
m_{\text {in }}=\frac{m_{\text {rail }}}{B(p, T)}\left(p_{B 1}-p_{A}\right)
$$

Once the leak is introduced into the system, the pressure rise

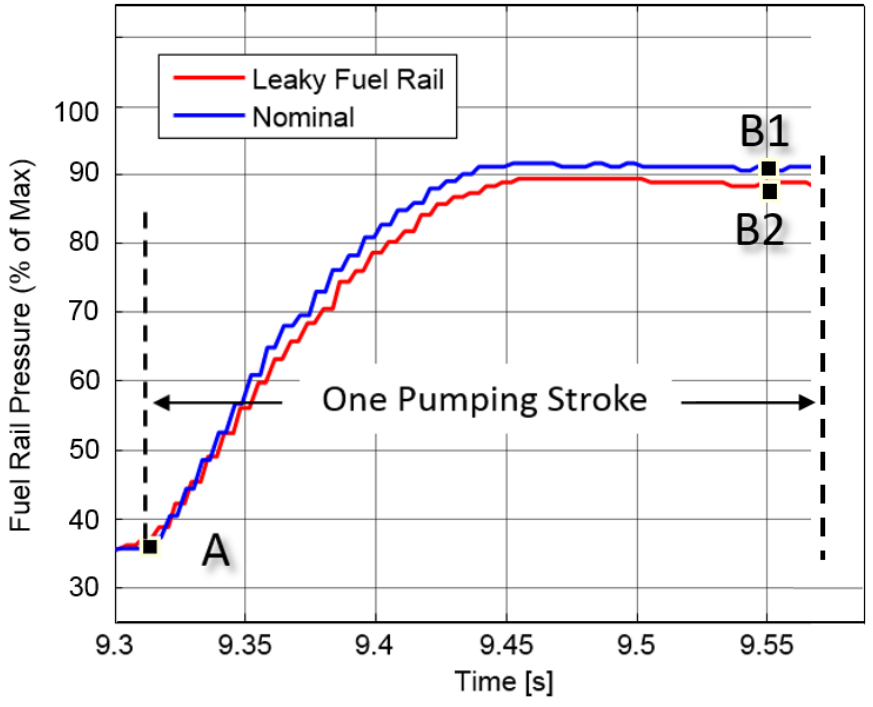

Figure 8. Pressure Rise during Engine Cranking with and without Leak Fault Being Injected.

within the pumping stroke from point $A$ to point $B_{2}$ is

$$
\Delta p_{\text {leak }}=p_{B 2}-p_{A}
$$

This allows us to rewrite the Equation (5) as,

$$
m_{\text {in }}-m_{\text {leak }}=\frac{m_{\text {rail }}}{B(p, T)}\left(p_{B 2}-p_{A}\right) .
$$

Combining Equation (7) and (9), the amount of fuel mass that leaked out during this pumping stroke is given by the following expression

$$
m_{\text {leak }}=\frac{m_{\text {rail }}}{B(p, T)}\left(p_{B 1}-p_{B 2}\right)
$$

given that the pressure started to rise from the same starting pressure $p_{A}$ for both cases. The leak rate can now be calculated by the following expression

$$
\dot{m}_{\text {leak }}=\frac{m_{\text {leak }}}{\Delta t}
$$

where $\Delta t$ is the time during of the the pumping stroke. Since pumping stroke time depends on the engine speed, using leak rate as a metric will eliminate the engine speed variation when evaluating fault severity.

The high pressure fuel pump is directly driven by the engine. Engine speed variations during cranking can cause variations in fuel mass pumped into the fuel rail, and thus the associated pressure rise corresponding to each pumping stroke. In order to distinguish the leak in fuel delivery system from variations caused by engine speeds, we carry out a sensitivity analysis that allows us to establish bounds on the smallest leak rate in the fuel delivery system that can be detected with good confi- 
dence and repeatability. Statistical analysis shown in Table 1 presents variations in the fuel mass pumped into the fuel rail during different pumping strokes. Nominal case and the case with a leaky fuel delivery system (with a fixed leak rate) are compared, where average fuel mass pumped into the fuel rail per pumping stroke is calculated by Equation (5).

Table 1. Pressure Rise Variations for Different Pumping Strokes During Engine Cranking.

\begin{tabular}{c|c|c|c}
\hline \hline Condition & $\begin{array}{c}\text { No. of } \\
\text { Pumping } \\
\text { Strokes }\end{array}$ & $\begin{array}{c}\text { Avg. Fuel } \\
\text { Mass (\% of } \\
\text { max.) }\end{array}$ & $\begin{array}{c}\text { Coeff. of } \\
\text { Variation }\end{array}$ \\
\hline \hline Nominal & 14 & 89 & $3.4 \%$ \\
\hline Leaky & 19 & 74 & $5.8 \%$ \\
\hline
\end{tabular}

The result shows small coefficient of variation (standard deviation/mean) for the nominal case, as well as the case where leak was injected into the fuel rail. Figure 9 shows that the mean average fuel mass (in terms of $\%$ of the maximum fuel that can be delivered per stroke) for the two cases described in Table 1 are separated by two standard deviations of their respective distributions. The difference between the mean fuel mass of the two cases is $15.5 \%$ (of the maximum fuel that can be pumped per stroke). Therefore, it can be claimed that the minimum mean leak that can be detected with a $95 \%$ confidence interval corresponds to a decrease of only a $15.5 \%$ with respect to the maximum fuel that can be pumped per stroke.

We do not know, based on our literature search, of any method that is employed by any auto-manufacturer designed to detect, and isolate fuel leaks. Fuel leak is typically detected based on fuel odor (because of excessive leakage), or by visual inspection. If there is excessive fuel leak, typically the on-board diagnostic that will eventually trigger is in fact designed to monitor the performance of the high pressure fuel pump. A leaking fuel system will require more fuel to be pumped into the fuel rail than nominal, and as a result the feedback control gain of the high pressure fuel pump will increase in order to achieve this. The feedback control gain of the high pressure fuel pump will eventually saturate to its maximum authority as the fuel leak continues to increase. At this point the high pressure pump can no longer compensate for the lost fuel mass due to leakage, thereby triggering its performance Diagnostic Trouble Code. The algorithm we have developed, has the capability to identify fuel system leak much earlier than this diagnostic. We ran multiple experiments with increasing level of fuel system leakage, until the probability density function of leaking system was separated from that of the nominal system with $95 \%$ confidence (see Figure 9). At this separation level, the fuel system leakage was calculated to be $74 \%$ of the maximum fuel that can be pumped in per stroke. Also, since the leaking system re- quires more fuel to be pumped into the fuel rail and this is achieved by an increase in the feedback control gain for the high pressure fuel pump, the control gain was observed to have increased by only $8 \%$ relative to its maximum available authority to compensate for the loss of fuel mass. The Diagnostic Trouble Code will trigger when the feedback control gain reaches $100 \%$ of the available authority.

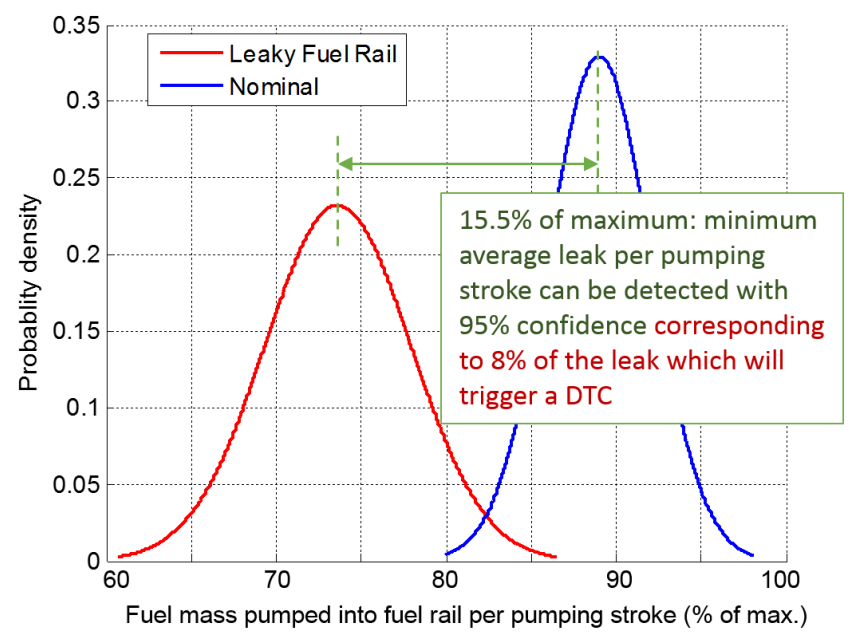

Figure 9. Distribution of Fuel Mass Per Pumping Stroke Nominal and Leaky Fuel Rails.

\subsection{Leak Detection at Decel Fuel Cutoff and Engine Shut- down}

When the vehicle is decelerating, e.g. when brakes are applied, fuel can be conserved by turning of the fuel injectors. This is practiced in various GM vehicles and is referred to as deceleration fuel cutoff or DFCO and is estimated to improve fuel economy by up to $2 \%$ ("Technology Helps Chevrolet Cruze Customers Save Fuel When Slowing Down”, 2011). During DFCO, or after engine shuts down at key off, or during the start-stop operation, the high pressure fuel pump stops pumping fuel into the fuel rail and no fuel is injected into the combustion chamber at the same time. Due to the check valve between the high pressure fuel pump and the fuel rail, fuel can't flow back to the pumping chamber. The fuel rail, therefore, becomes a sealed reservoir with a certain amount of fuel trapped insides. The trapped fuel starts to absorb heat from the engine and in the absence of any leak from the fuel rail, it's pressure starts rising gradually due to thermal expansion as shown in Figure 10.

The pressure rise due to thermal expansion can be described by the equation (Tipler \& Mosca, 2007),

$$
\Delta p_{t e m p}=K B\left(1-\frac{1}{1+\beta \Delta T}\right)
$$

where $\beta$ is the volumetric coefficient of thermal expansion, $B$ 


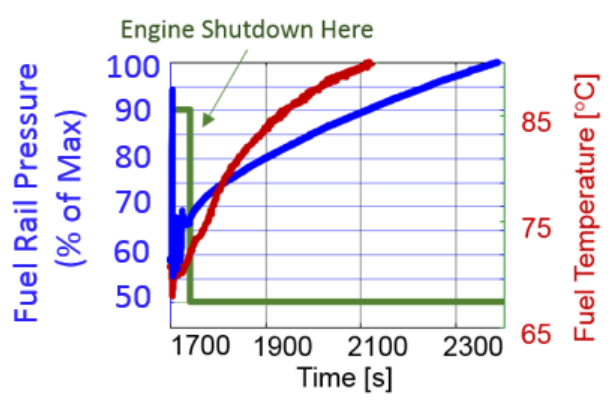

Figure 10. Pressure Rise after Engine Shutdown Caused by Thermal Expansion.

is the Bulk Modulus of Elasticity and $K$ is a system-depended calibratable coefficient. Typically, the volumetric coefficient of thermal expansion for gasoline is 0.00095 per ${ }^{\circ} \mathrm{C}$ (Tipler \& Mosca, 2007), which allows us the following approximation,

$$
1+\beta \Delta T \approx 1
$$

Therefore, the pressure change due to thermal expansion in Equation (12) can be approximated by the following linear relationship

$$
\Delta p_{t e m p}=(K B \beta) \Delta T
$$

As the system ages (e.g. worn out pressure seals, leaky injectors), the fuel rail pressure may increase slower or even decrease during DFCO, engine shutdown, and stop-start operation. Figure 11 shows the fuel rail pressure change after engine shuts down with nominal fuel rail (blue curve) and when a leak is induced (red curve). The blue curve shows that the fuel rail pressure increased gradually after engine shutdowns due to thermal expansion, while the red curve shows that the pressure decreased significantly due to the fuel leaking out of the fuel rail.

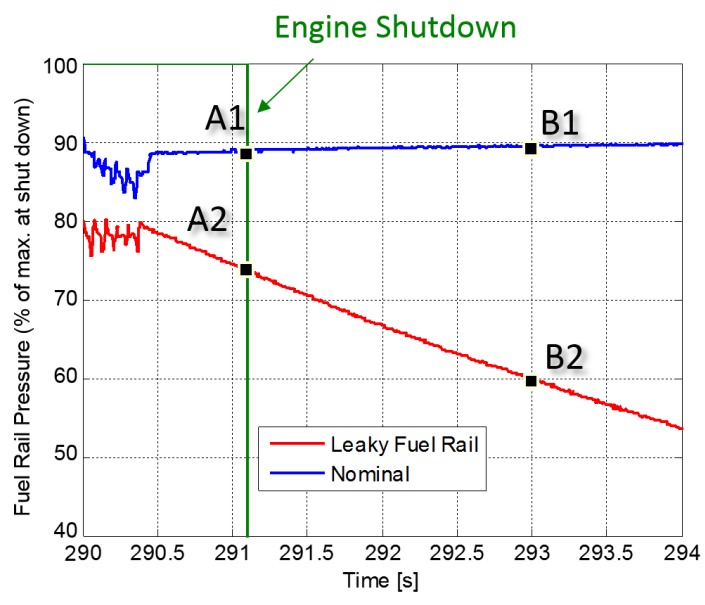

Figure 11. Fuel Rail Pressure Change after Engine Shutdown With and Without Induced Leak.
For the nominal case, as shown by the blue curve, the pressure change in fuel rail $\left(\Delta p_{t e m p}\right)$ was only due to thermal expansion and therefore can be written as

$$
\Delta p_{t e m p}=p_{B 1}-p_{A 1}
$$

For the case where a leak was induced, the pressure change was caused by thermal expansion as well as fuel leakage. Therefore, the change is pressure can be expressed as

$$
\Delta p_{\text {temp }}+\Delta p_{\text {leak }}=p_{B 2}-p_{A 2}
$$

where $\Delta p_{\text {leak }}$ is the change in fuel rail pressure attributed to the fuel leakage. Using Equation (16) and Equation (4), the leak rate can be calculated as

$$
m_{\text {leak }}=\frac{m_{\text {rail }}}{B(p, T)}\left(p_{A 2}-p_{B 2}+(K B \beta) \Delta T\right)
$$

Then the leak rate can be calculated by Equation (11), where $\Delta t$ is a pre-defined time period.

\subsubsection{Leak Severity Evaluation}

Leak severity can be evaluated by analyzing the pressure change rate during DFCO, engine shutdown, start-stop, and any other cases when neither there is any fuel entering into the fuel rail from the high pressure fuel pump, nor being injected out into the combustion chamber through the injectors. Fuel leak from the fuel rail during the condition described above can be separated into two subcategories:

- fuel flows out of the fuel rail, where the flow rate and fuel rail pressure are described by Bernoulli's equation, and

- remaining fuel expands in the fuel rail due to pressure drop, which is governed by Bulk Elastic Modulus.

Note that only the condition when the fuel rail pressure is larger than the vapor pressure of gasoline $(>0.5 \mathrm{MPa}$ (Nadkarni \& Nadkarni, 2007)) is investigated to guarantee the fuel is in compressed liquid state. From the modified Bernoullis Equation (Green, 2007) we have the following relationship for fluid mass flow rate through an orifice

$$
\frac{d m}{d t}=C_{d} A \sqrt{2 \rho\left(P-P_{a t m}\right)}
$$

where $C_{d}$ is the discharge coefficient, $A$ is the cross-sectional area of the orifice, $\rho$ is the fluid density, $P$ is the pressure of fluid on the pressurized side of the orifice, and $P_{a t m}$ is the atmospheric pressure. Equation (3) earlier showed how the rate of change of pressure in the fuel rail can be expressed in terms of fuel mass in and out of it. In the absence of any fuel mass being pumped into the fuel rail, this relationship can be rewritten as follows

$$
\frac{d m}{d t}=-\frac{m_{\text {rail }}}{B} \frac{d P}{d t}
$$


For a small enough time interval (small $\Delta t$ ), we can assume that $m_{\text {rail }}$ remains constant since the amount of fuel that leaks out of system is insignificant. This allows us to combine Equation (18) and (19) and we can write the dynamics of pressure change, when the fuel rail is only subject to leak, as follows:

$$
\frac{m_{\text {rail }}}{B} \frac{d P}{d t}+C_{d} A \sqrt{2 \rho\left(P-P_{a t m}\right)}=0
$$

Define gauge pressure $p$ as

$$
p=P-P_{a t m},
$$

then we can rewrite Equation (20) as the following nonlinear differential equation:

$$
\frac{d p}{d t}+k \sqrt{p}=0
$$

where

$$
k=\frac{B C_{d} A \sqrt{2 \rho}}{m_{\text {rail }}}
$$

The solution corresponding to Equation (23) can be given as

$$
p=\frac{1}{4}(k t-c)^{2}+C 1
$$

where $c$ is a system dependent parameter, and $C 1$ is a constant of integration. The solution can be verified by plugging back into Equation (23). The solution in Equation (24) describes the fuel rail pressure change when the fuel rail is only subjected to leak starting at time $t$ until the fuel pressure drops below the vapor pressure. Figure 12 (bottom) shows a plot that captures the pressure drop in fuel rail when engine shuts down with leak induced into the fuel rail. Figure 12 (top) shows how the drop in measured fuel rail pressure (red curve) is estimated by a curve (black) fitted by equation of the form given in (24). The coefficient of determination, $R^{2}$, is 0.99 which highlights the fact that the estimation is extremely good! In the example shown, $k=0.63$ can be used as an indicator of the leak severity. The higher the value of $k$, the faster the pressure drops in a given system indicating a bigger sized orifice for fuel leak.

\section{Leak Detection, Isolation, and Prognosis of High Pressure Fuel Delivery System}

Based on the leak detection during engine cranking, at DFCO, stop-start operation, or after engine shutdown, leak in the fuel delivery system can be further localized. Before start of fuel injection during engine cranking, if the calculated leak rate is significant, i.e. larger than the minimum leak rate that can be detected within $95 \%$ confidence interval, we can deduce that fuel is leaking out of the fuel rail/fuel injectors or through the pump. The fuel pump can experience internal leakage or loss of pumping efficiency causing slower pressure rise in the fuel rail. On the other hand, if leak is detected at DFCO, stop-
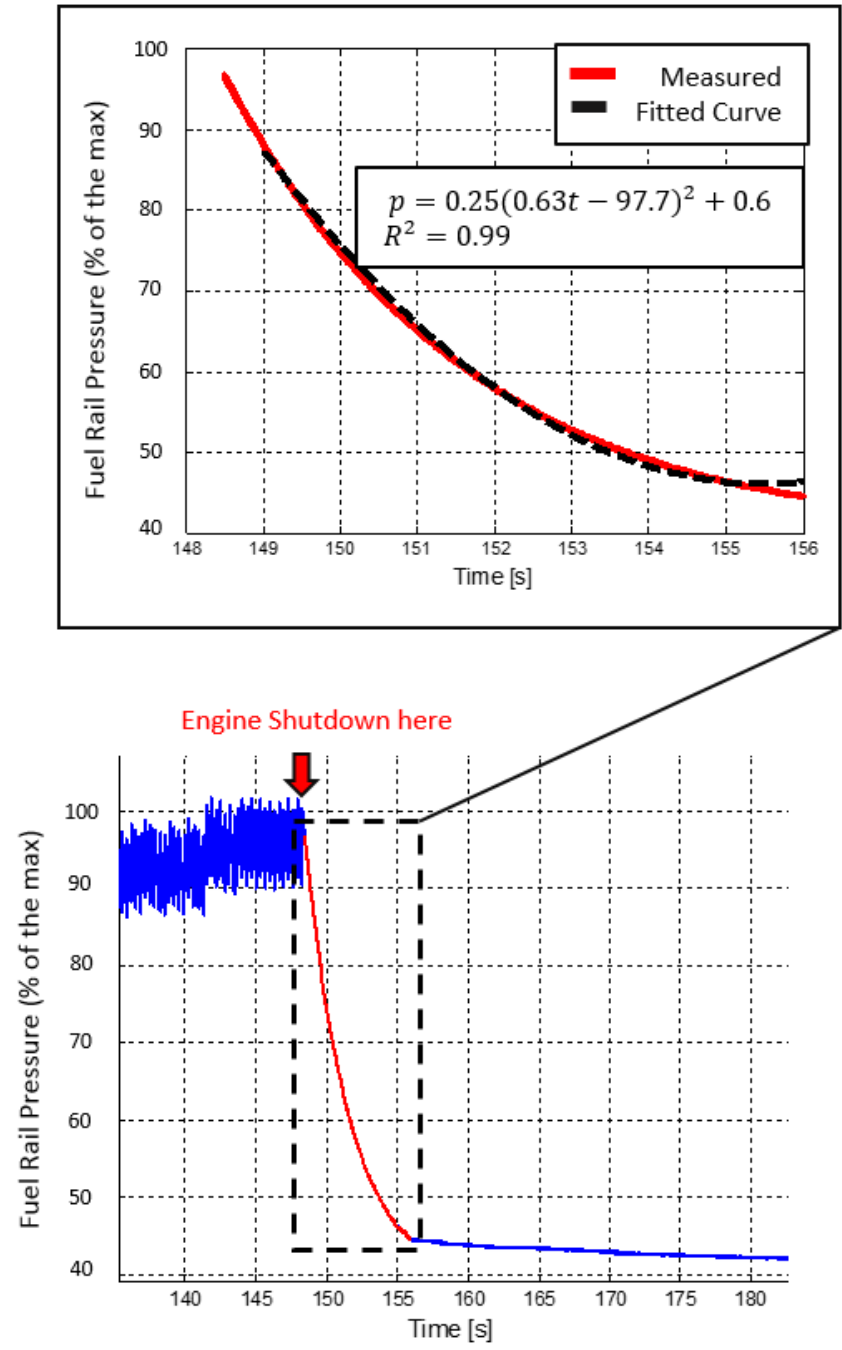

Figure 12. Pressure Drop after Engine Shutdown with Leak Fault Being Injected against the Fitted Pressure Curve.

start operation, or after engine shutdown, the leak can only happen in fuel rail/injectors since the fuel rail is isolated from the high pressure fuel pump by a check valve.

Let $\dot{m}_{1}$ be the leak rate calculated during engine cranking, and $\dot{m}_{2}$ be the leak rate calculated at DFCO, stop-start operation, or after engine shutdown, the leak location can be further identified as follows:

- If $\dot{m}_{1}=\dot{m}_{2}$ : leak is only from fuel rail/injectors.

- If $\dot{m}_{1}>\dot{m}_{2}$ : leak is not only from fuel rail/injectors but may also be from high pressure pump - equivalently the high pressure pump may have also lost its pumping efficiency.

- If $\dot{m}_{2}=0$ : no leak is from fuel rail/injectors, and the leak can only be attributed to the high pressure fuel pump.

We note here that while the situation $\dot{m}_{1}<\dot{m}_{2}$ is not phys- 
ically possible, erroneous sensing could still lead to such a conclusion in which case we generalize and classify it as a new/unknown failure mode.

\section{Conclusion}

Leak fault studied on a test vehicle during engine cranking, at deceleration fuel cutoff, and after engine shutdown suggested that leak rate can be calculated to further identify the leak location within the high pressure fuel delivery system. Leak severity can be evaluated based on the analytical solution of the pressure profile after engine shutdown fitted against the measured pressure data. Drawing insights from test studies and simulation results mentioned above, prognosis algorithm along with leak fault isolation and identification schemes were developed for high pressure fuel delivery system.

\section{REFERENCES}

Baude, R., Froehlich, A., W., H., H., M., \& E., M. (2008). The new audi $6.01 \mathrm{v} 12 \mathrm{tdi}$, the ultimate performance diesel. In 29th international vienna motor symposium.

Digital in 2017: Global overview. (2017). Available:https://wearesocial.com/ special-reports/digital-in-2017 -global-overviewl. (Accessed: 08-Oct-2017)

Ferguson, C. R., \& Kirkpatrick, A. T. (2015). Internal combustion engines: applied thermosciences. John Wiley \& Sons.

Green, D. W. (2007). Perrys chemical engineering handbook. McGrawHill Professional, 2-83.

He, Y., Liu, Z., Stahl, I., Zhang, G., \& Zheng, Y. (2016). Comparison of stochastic pre-ignition behaviors on a turbocharged gasoline engine with various fuels and lubricants (Tech. Rep.). SAE Technical Paper.

Hoffmann, G., Befrui, B., Berndorfer, A., Piock, W. F., \& Varble, D. L. (2014). Fuel system pressure increase for enhanced performance of gdi multi-hole injection systems. SAE International Journal of Engines, 7(201401-1209), 519-527.

Kang, J., \& Hu, H. (2004). Vibration detection \& diagnosis for high-pressure fuel pipe of diesel engineer. In Information acquisition, 2004. proceedings. international conference on (pp. 127-129).

Krogerus, T. R., Hyvönen, M. P., \& Huhtala, K. J. (2016). A survey of analysis, modeling, and diagnostics of diesel fuel injection systems. Journal of Engineering for Gas Turbines and Power, 138(8), 081501.

Light-duty automotive technology, carbon dioxide emissions, and fuel economy trends: 1975 through 2016. (2016).

https: / / www . epa.gov/fueleconomy /

light-duty-automotive-technology

-carbon-dioxide-emissions-and-fuel

-economy-trends-1975-0. (Accessed: 16-Oct-
2017)

Nadkarni, R., \& Nadkarni, R. (2007). Guide to astm test methods for the analysis of petroleum products and lubricants. ASTM International West Conshohocken.

Sarwar, A., Sankavaram, C., \& Lu, X. (2017). Control adaptation approach for fault detection and isolation in sidi high pressure fuel pump. In Prognostics and health management (icphm), 2017 ieee international conference on (pp. 117-123).

Schaschke, C., Fletcher, I., \& Glen, N. (2013, July). Density and viscosity measurement of diesel fuels at combined high pressure and elevated temperature. Processes, 1(2), 30-48.

Silver, D., Huang, A., Maddison, C. J., Guez, A., Sifre, L., Van Den Driessche, G., ... others (2016). Mastering the game of go with deep neural networks and tree search. nature, 529(7587), 484-489.

Technology helps chevrolet cruze customers save fuel when slowing down. (2011, June).

Available: https://media.gm.com/

content/media/us/en/gm/news.detail

.html/content/Pages/news/us/en/2011/

Jun/0624\{\_\} cruze.html. (Accessed: 13-Oct2017)

Tipler, P. A., \& Mosca, G. (2007). Physics for scientists and engineers. Macmillan.

World internet users statistics and 2017 world population stats. (2017). Available:http:// www. internetworldstats. com/stats.htm. (Accessed: 08-Oct-2017)

Zhao, H. (2009). Advanced direct injection combustion engine technologies and development: Diesel engines. Elsevier.

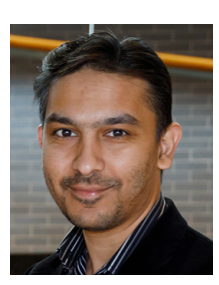

Azeem Sarwar received his Bachelor's Degree in Mechanical Engineering with highest honors from National University of Sciences and Technology, Pakistan, in 2000 receiving President's, as well as, Commandant's gold medals. He then worked in the energy sector for about 4 years working as a consultant for various oil and gas exploration and production companies and regulatory authorities before starting his graduate studies at the University of Illinois at Urbana Champaign. From Illinois, he received a Master's Degree in Mechanical Engineering in 2006, a Master's Degree in Mathematics in 2008, and a PhD in Mechanical Engineering in 2009. After graduating from Illinois, he worked as a Research Fellow at the University of Maryland College Park with the Institute of Systems Research. One of the devices he developed there featured as Image/Video of the month at magneticmicrosphere.com in June 2012. Since 2014, he has been working as a Senior Researcher at General Motors Research and Development Center where he is 
developing prognostic technologies for automotive applications, and have filed more than 30 Records of Invention so far, with 21 patent applications. He is a recipient of the Canadian Commonwealth Scholarship, and the NSF IGERT Fellowships. He has made numerous national and international presentations about his work. His work has featured in one book chapter, three invited journal publications, and more than 25 peer reviewed articles. He is a recipient of IEEE PHM Society's Best Paper Award. His research interests include fault modeling, fault diagnosis and prognosis, machine learning, and artificial intelligence.

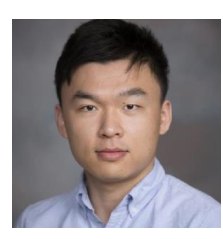

Xiangxing Lu is assistant researcher working with Vehicle Heath Management Group at General Motors Global R\&D Center in Warren, Michigan since 2016 where has been supporting various diagnosis and prognosis projects. He received his M.S. and B.S. degrees in Mechanical Engineering from University of Michigan in 2015 and Shanghai Jiao Tong University in 2014, respectively. His research interests include advanced modeling and control, fault diagnosis and prognosis, and machine learning. 